\title{
$N 88-22399$
}

\section{COMPUTATIONAL STRUCTURAL MECHANICS FOR ENGINE STRUCTURES}

\author{
Christos C. Chamis \\ St ructures Division \\ NASA Lewis Research Center
}

\begin{abstract}
The computational structural mechanics (CSM) program at Lewis encompasses the formulation and solution of structural mechanics problems and the deve1opment of integrated software systems to computationally simulate the performance, durability, and life of engine structures. It is structured to supplement, complement, and, whenever possible, replace costly experimental efforts. Specific objectives are to investigate unique advantages of parallel and multiprocesses for reformulating and solving structural mechanics and formulating and solving multidiscipiinary mechanics and to develop integrated structural system computational simulators for predicting structural performance, evaluating newly developed methods, and identifying and prioritizing improved or missing methods.
\end{abstract}


The general content of the Lewis CSM program plan is summarized in the accompanying block diagram. The long-range objective of the program is the full engine structural simulation. It draws on methodology developed under research and development programs and the HOST Program over the past 10 years. This methodology is multidisciplinary and includes high temperature structures specialty analysis methods, rotating system dynamics, advanced components, and durability and 1 ife.

FY 86

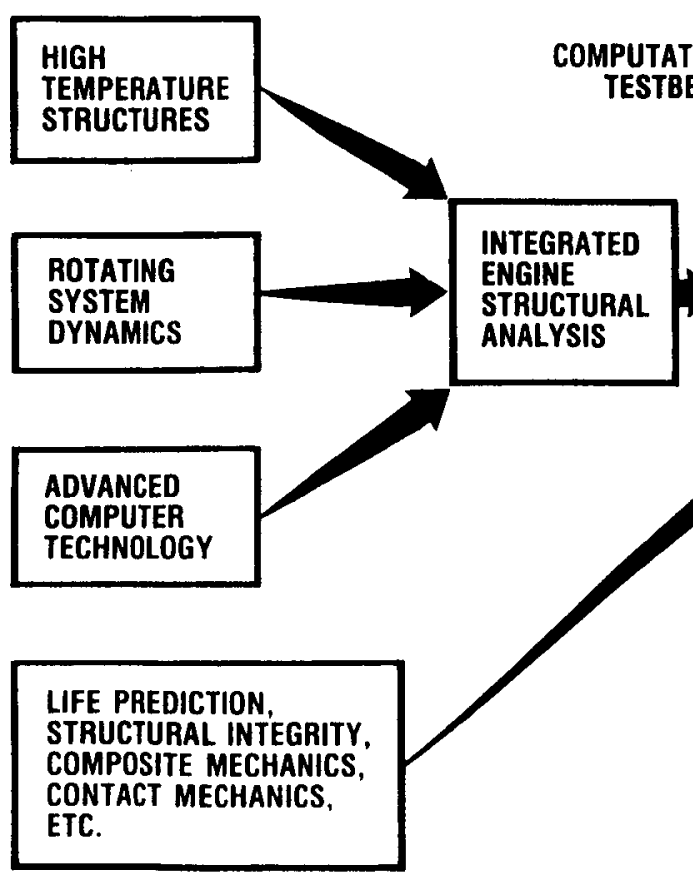

FY 90-92

ENGINE STRUCTURES PERFORMANCE/INTEGRITY SIMULATOR (ESPIS)

FULL ENGINE

STRUCTURAL

MISSION

ANALYSIS
KEY PROGRAM ELEMENTS

- STRUCTURAL ANALYSIS METHODS

- adVANCED COMPUter technologr

- COMPUTATIONAL TESTBED/ESCS

CD-88-32972 


\section{COMPUTATIONAL STRUCTURAL METHODS IDENTIFIED}

METHODOLOGY - IMPROVED OK MISSING

An important part of the CSM for engine structures program is the identification of methodology which needs improvement or is missing. This methodology includes several key elements as 1 isted in the accompanying chart. For example, boundary elements for hot fluid and structure interaction is natural since the boundary elements are formulated to match specified surface conditions and satisfy the interior field equations exactly.

- BOUNDARY ELEMENTS FOR 3-D INELASTIC ANALYSIS

- BOUNDARY ELEMENTS FOR HOT FLUID AND STRUCTURE INTERACTION

- EFFICIENT HYBRID ELEMENTS

- ADAPTIVE TRANSITIONAL FINITE ELEMENTS

- COMPUTATIONAL COMPOSITE MECHANICS

- COMPUTATIONAL CONTACT MECHANICS

- COUPLE COMPUTATIONAL SIMULATION WITH OPTIMIZATION 
Another important part of the CSM program is to identify alternative methodology for computational simulation such as (1) the probabilistic approach for quantifying the uncertainties with all variables of structural analysis and design and (2) alternative methods for formulating structural mechanics problems. Some of the them have already been identified and are 1 isted below

- PROBABalistic OR STOCHASTIC:

- VARIATIONAL PRINCIPLES FOR PROBABILISTIC FINITE ELEMENT

- PROBABILISTIC STRUCTURAL ANALYSIS METHODS

- PROBABILISTIC FRACTURE MECHANICS

- ALTERNATIVE FORMULATIONS:

- MULTIPARALLEL PROCESSORS FOR MULTIDISCIPLINARY MECHANICS PROBLEMS

- SPECIALTY FUNCTIONS FOR SINGULAR MECHANICS PROBLEMS

- COUPLED CONSTITUTIVE RELATIONSHIPS

- DEDICATED EXPERT SYSTEMS 
A major part of the Lewis CSM program is the development of engine structures computational simulator (ESCS). ESCS integrates discipline specific methodology and computer codes developed under research and technology programs as indicated below. ESCS-predicted results will be postprocessed to make assessment of engine structural performance in terms of the items listed in the block at the right.

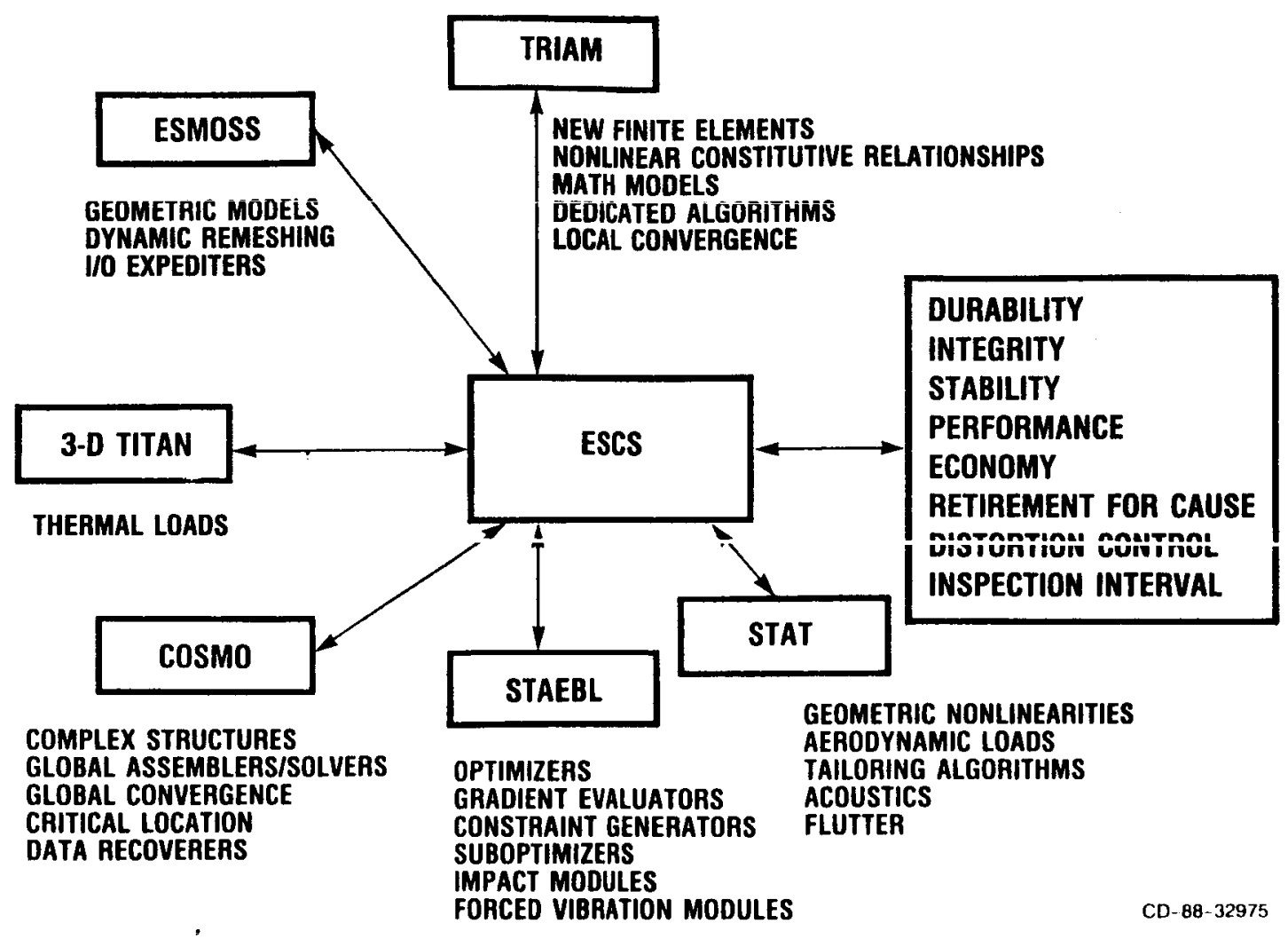


ESCS is modular with an expert-systen-driven executive module. It includes interfacing modules, a database, and its manager. A schematic of the ESCS present status configuration is shown in the accompanying chart. The interface module provides the logic to merge different analysis models as well as loading conditions to the analysis models. The analysis module includes advanced analys is methods such as specialty finite elements (threedimensional inelastic analysis), mixed elements (MHOST), and boundary elements (BEST3-D). It also includes NASTRAN and structures optimization (STAEBL).

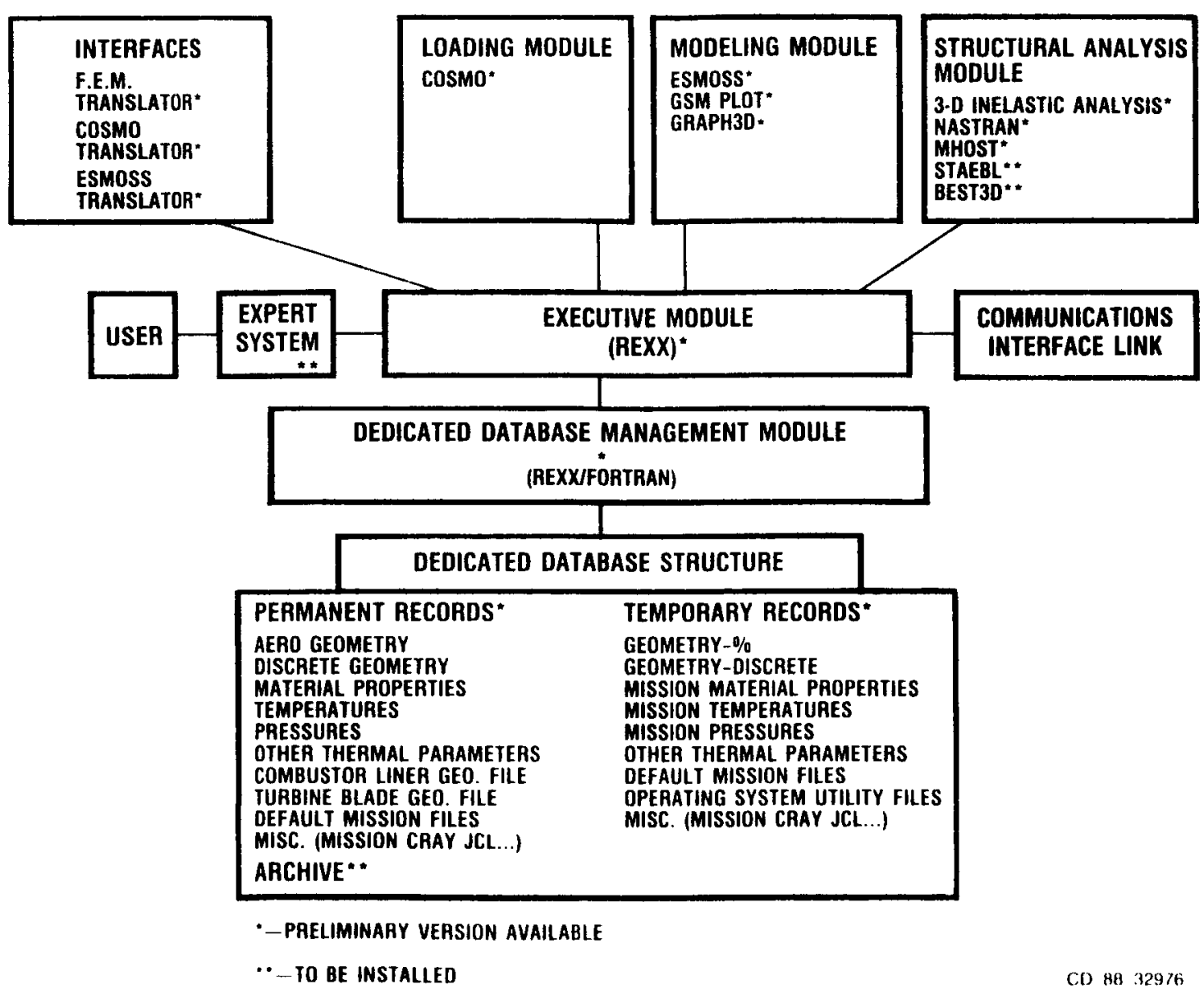




\section{ESCS CONFIGURED FOR ENGINE STRUCTURES FROM COMPONENT TO ENGINE}

ESCS is configured to computationally simulate the structural performance of engine structures: (1) subcomponents, (2) components, (3) subassemblies, (4) assemb1ies, and (5) integrated systems for mission specified requirements. These are shown below from bottom left to top right, respectively.

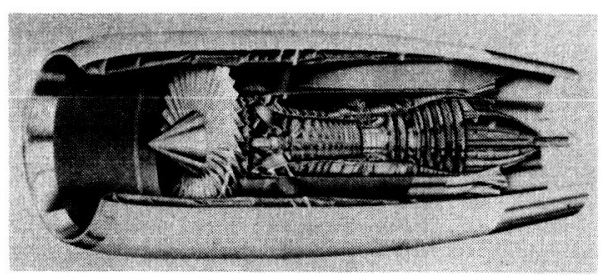

ENGINE

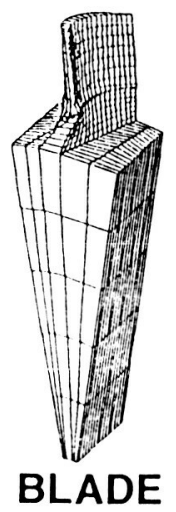

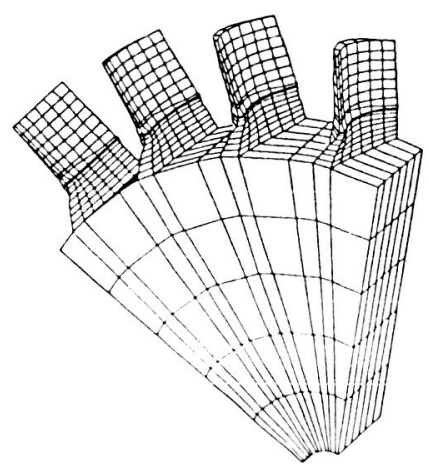

ROTOR SECTOR

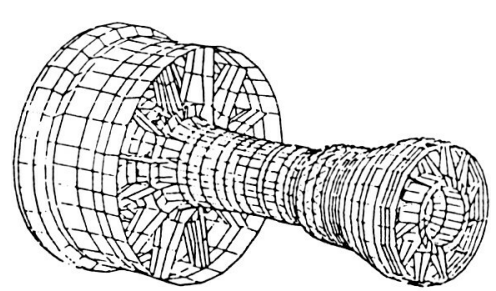

FINITE ELEMENT MODEL

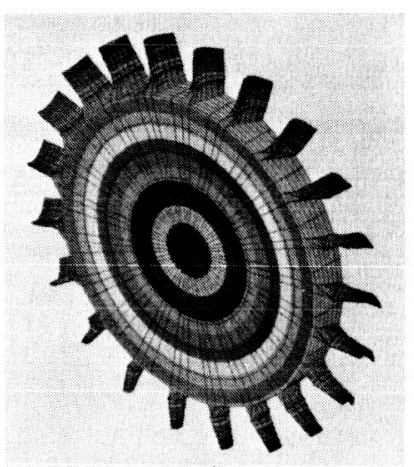

ROTOR STAGE

$C D-88-32977$

ORIGINAL PAGE IS

OF. POOR QUALITY 
The loads on the blades (temperatures, pressures, and rotating speeds) are determined by an engine loads module (COSMO in the ESCS schematic). This module is based on engine thermodynamics. The temperatures and pressures are predicted on the surface at user-selected span stations. The accompanying chart is a typical example for temperatures. The blade has been unfolded for 3-D plotting presentation. Pressures and speeds can be similarly represented.

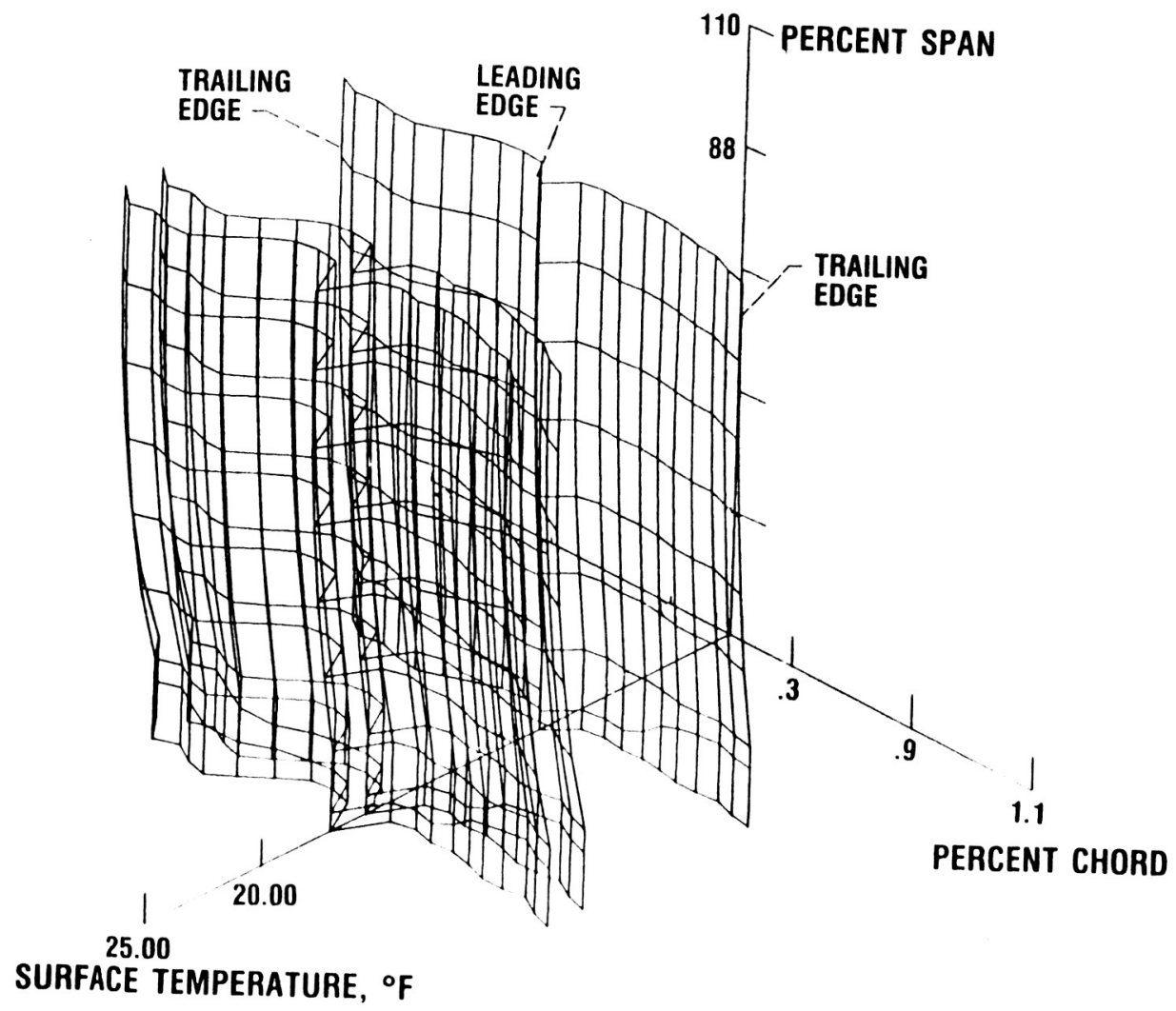

CD- $88-32978$ 


\section{DEFORMATION OF TURBINE BLADE UNDER FLIGHT CONDITIONS - A SAMPLE ESCS CASE}

The ESCS executive module couples the loads module with the analysis-modeling module and with the analysis module through module-communication links and proceeds to determine the blade structural response at the preselected times during the mission. Results from such an analysis for the displacements of a turbine blade are shown below for three mission conditions.

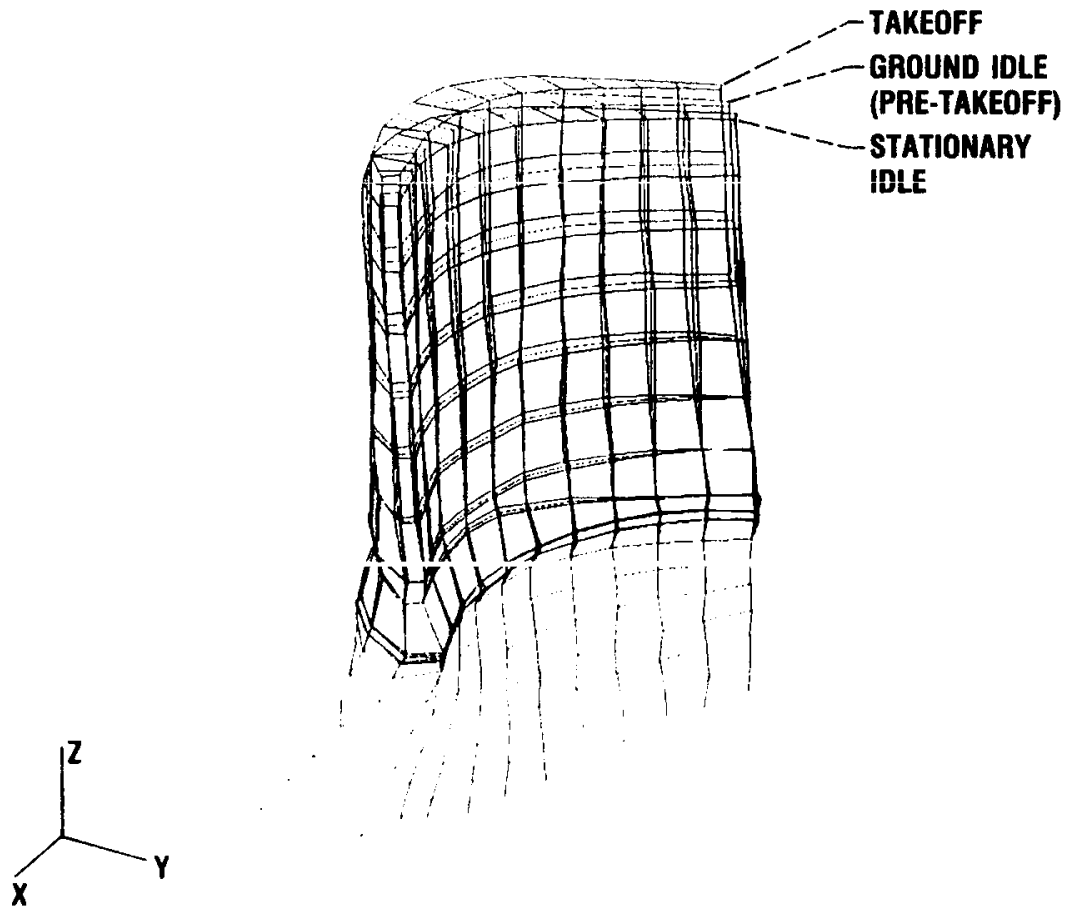

CD-88-32979 
ESCS has two finite-element analysis modules at its present status - MSC/NASTRAN and MHOST. Results predicted by these two analysis modules are compared in the accompanying chart. The predicted results for the blade airfoil displacements from the two analysis modules for combined mechanical and thermal loads are indistinguishable.

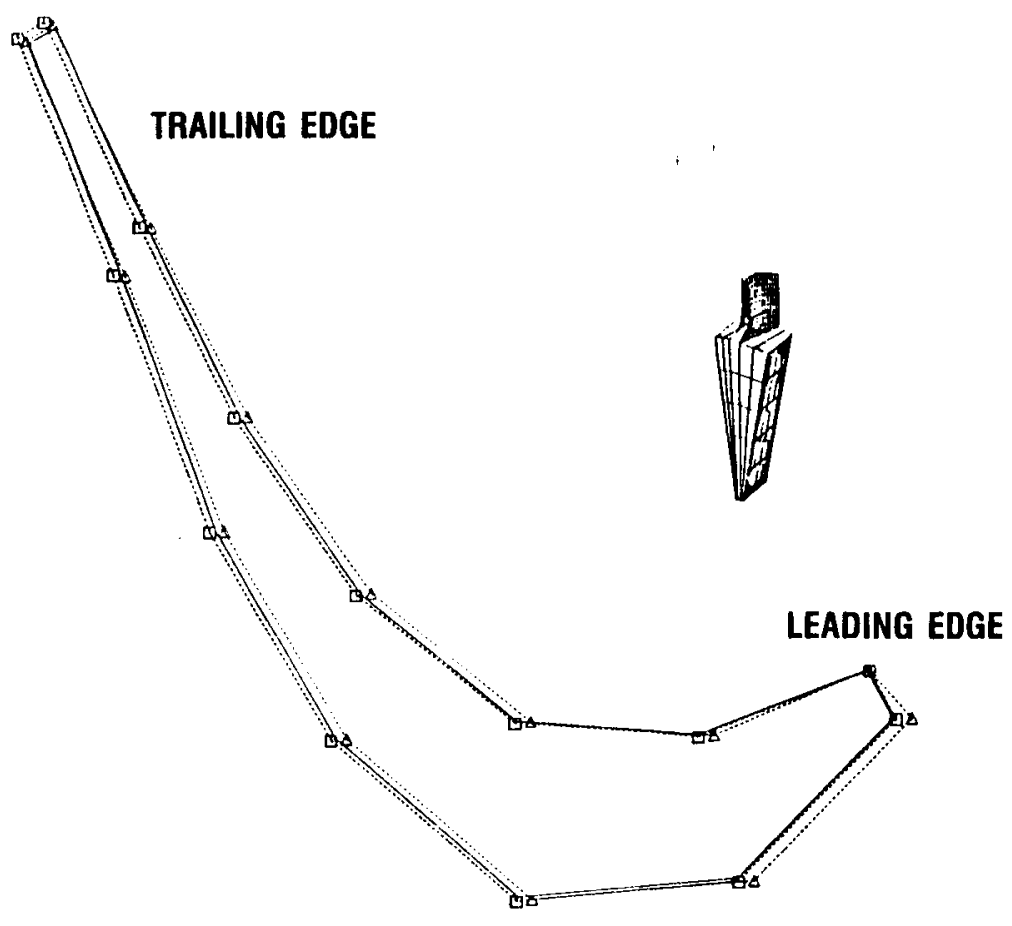


ESCS postprocesses analysis results for computer graphics display. Examples include a single component in this chart at three stages during the mission: ground idle, takeoff, and cruise. The dynamic motion of the blade is assessed by comparing it with the reference state (stationary position in the figure).

\author{
ORIGINAL PAGE IS \\ OF POOR QUALITY
}

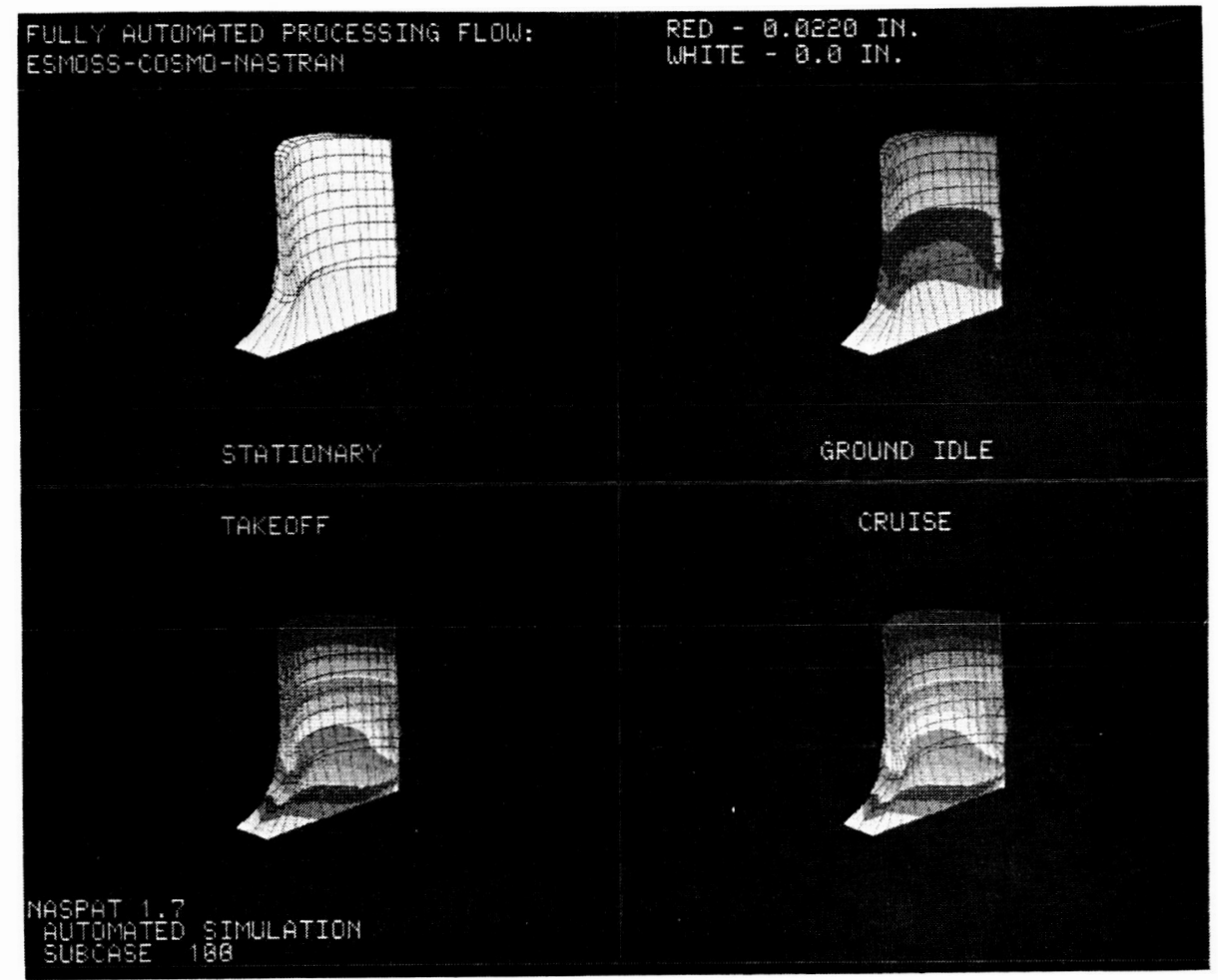

CD-88-32981 
The structural dynamic response of blades assembled in a bladed rotor is different from that of an individually simulated blade. The dynamic motion of a bladed rotor determined using ESCS is shown below at the takeoff conditions.

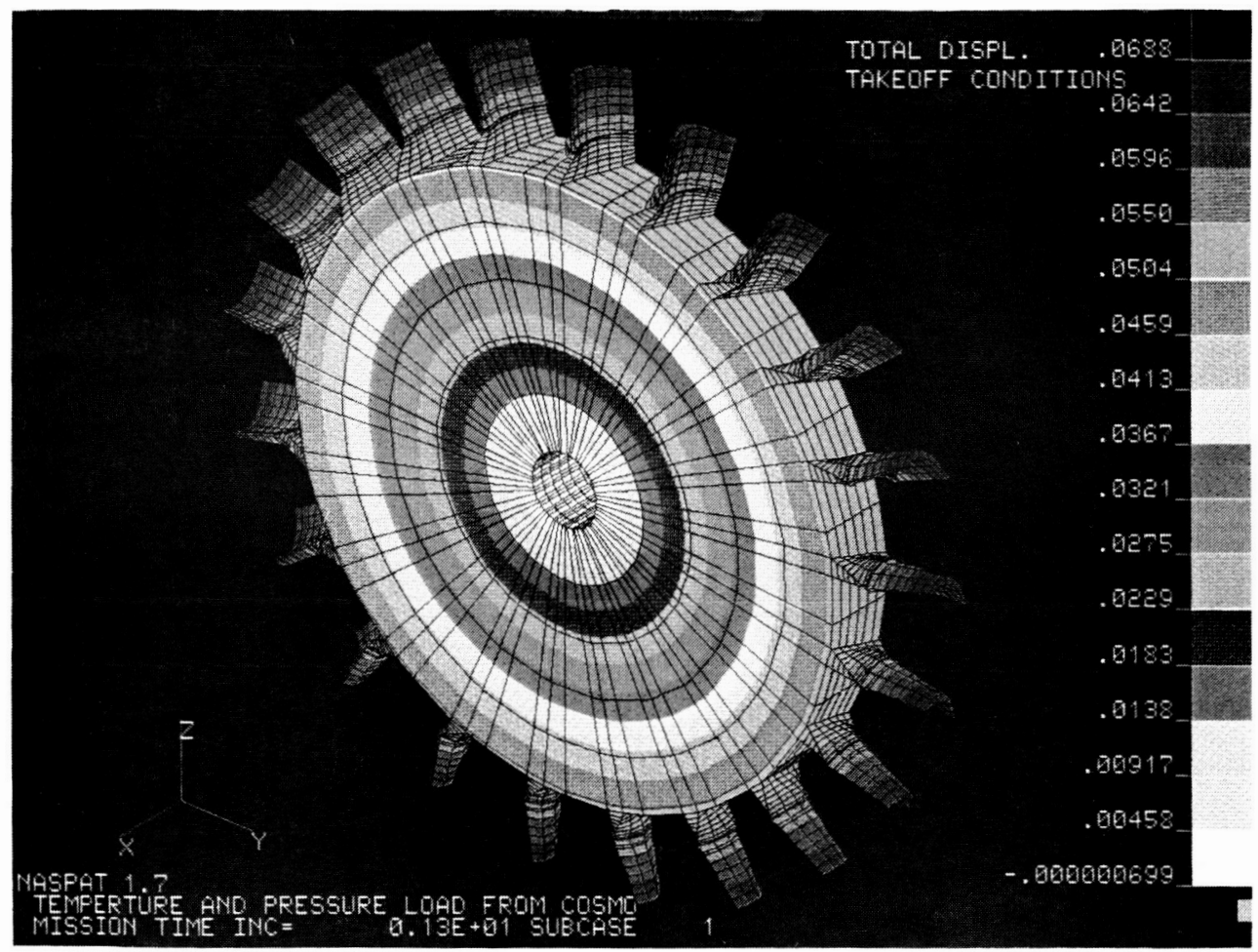

CD-88-32982 
The structural response can be predicted throughout the mission. Representative results for blade-tip radial displacement are shown graphically at identifiable stages during the flight for corresponding pressures, temperatures, and centrifugal loadings. These types of results can be obtained for any point in the component included in the simulation. The significance of having structured response throughout the mission is that all dynamic interactions are properly accounted for, and the stress-strain results are suitable for life assessments.

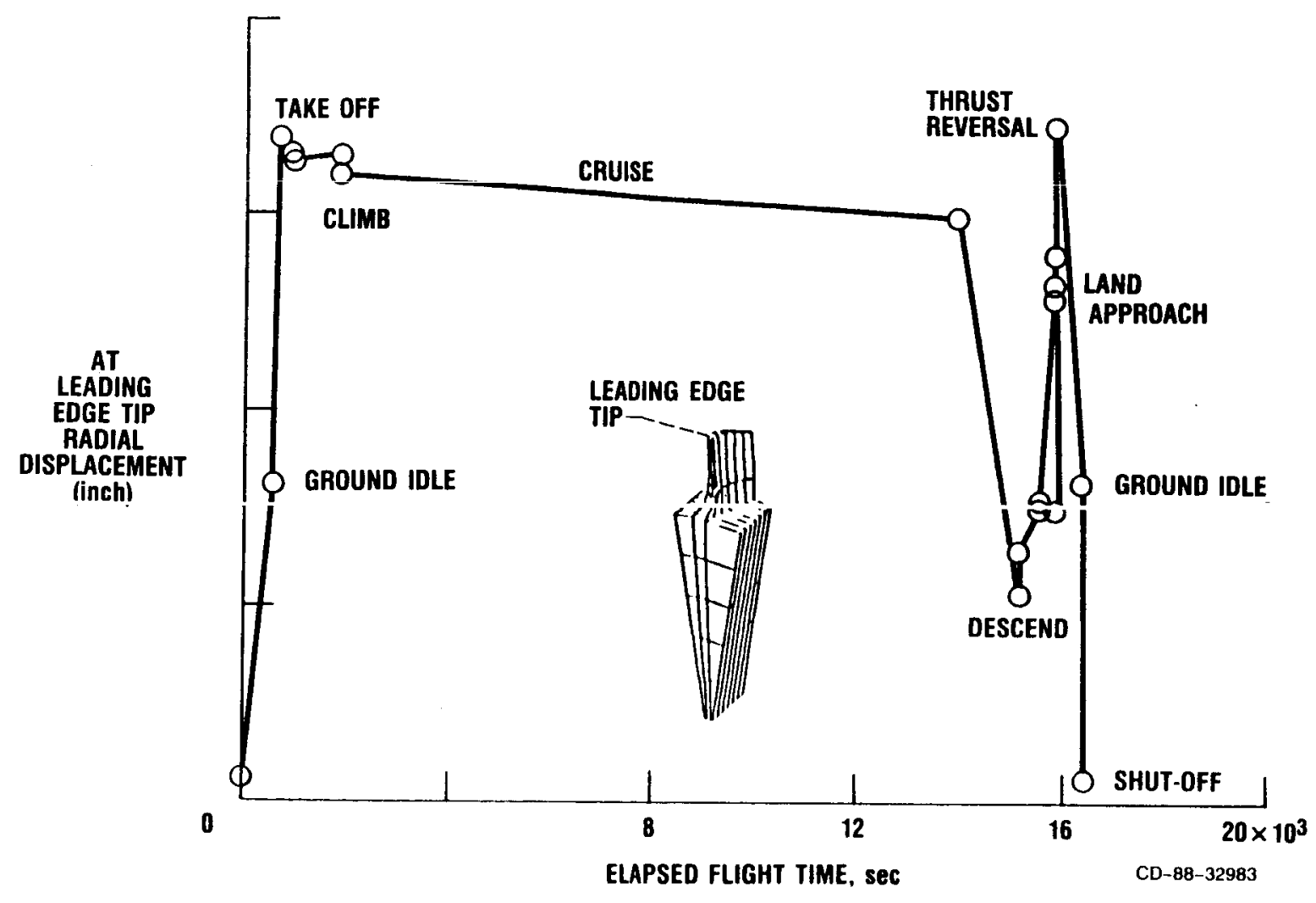


The 1ong range objective of the ESCS is to provide a computational simulation that parallels and replaces, in part, the current development methods which make extensive use of experimental procedures. The parallel between the current development procedures and ESCS are depicted below. ESCS will minimize the effort expended from initial design to engine builds and will often result in more cost effective engine builds for the same engine performance.

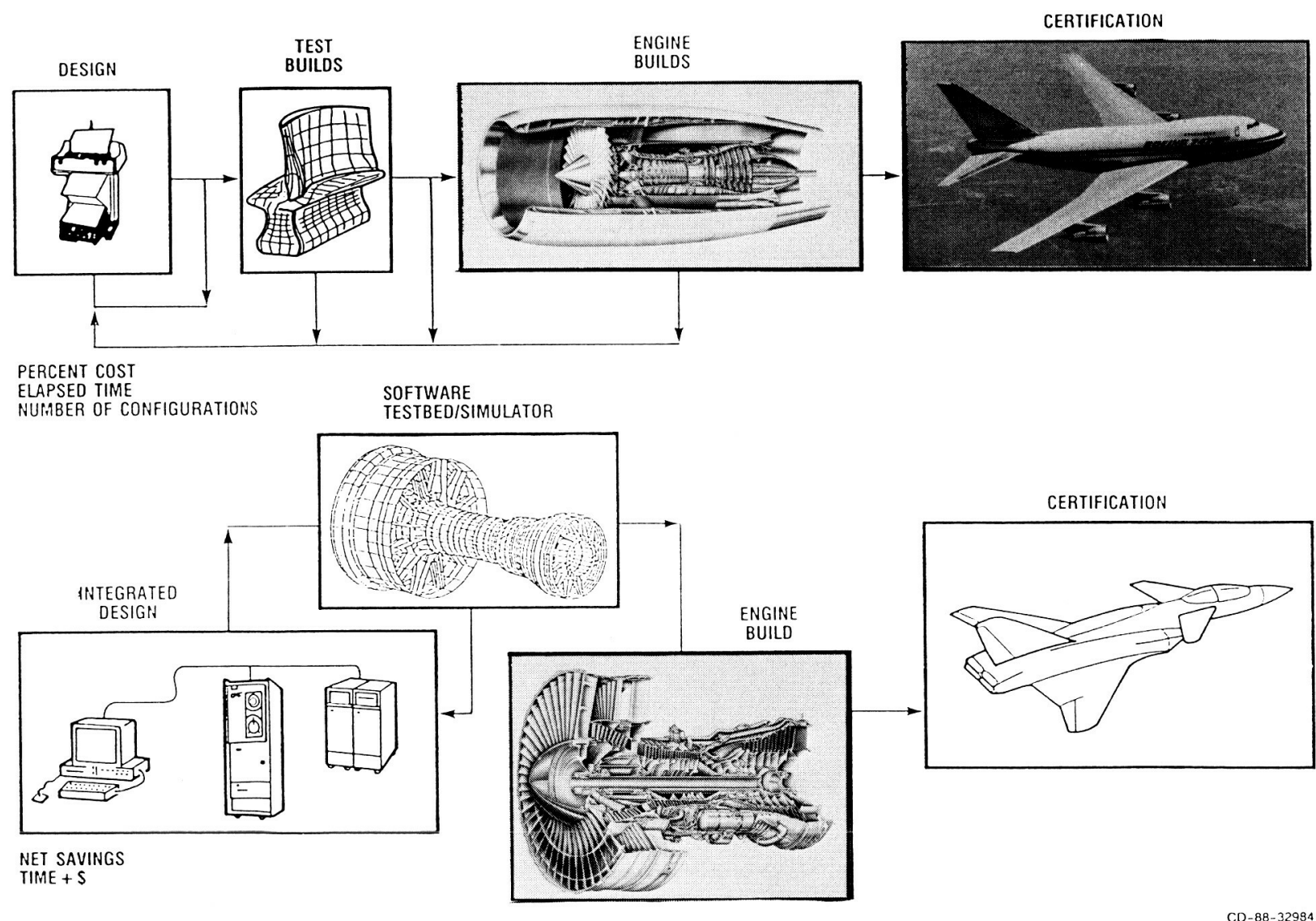


The anticipated benefits to aerospace industry of having and exercising ESCS are suminarized in the accompanying chart using qualitative terms. Engine manufacturers have cost estimates for each of the items in the chart based on their own development experience. Suffice it to say that each item runs into multimillions of dollars

- REDUCED DEVEIOPMENT TIME AND COSTS

- FEWER DEVELOPMENT ENGINE BUILDS

- LONGER LIFE COMPONENTS

- REDUCED LIFE CYCLE COSTS ON COMPONENTS

- REDUCED COMPONENT AND ENGINE WFIGHT

- IMPROVEd ENGINEERING PRODUCTIVITY

- INCREASED PERFORMANCE 